\title{
Maximizing Benefits from Maintenance Pemetrexed with Stereotactic Ablative Radiotherapy in Oligoprogressive Non-Squamous Non-Small Cell Lung Cancer
}

\author{
Shao-Lun Lu ${ }^{a}$ Feng-Ming Hsu ${ }^{b}$ Kuan-Yu Chen ${ }^{c}$ Chao-Chi Hoc \\ James Chih-Hsin Yang ${ }^{b} d$ Jason Chia-Hsien Cheng ${ }^{b, d}$ \\ aDivision of Radiation Oncology, Department of Medical Imaging, National Taiwan \\ University Hospital Hsin-Chu Branch, Hsinchu City, Taiwan; ${ }^{b}$ Department of Oncology, \\ National Taiwan University Hospital, Taipei, Taiwan; ' $D$ epartment of Internal Medicine, \\ National Taiwan University Hospital, Taipei, Taiwan; ${ }^{d}$ Graduate Institute of Oncology, \\ National Taiwan University College of Medicine, Taipei, Taiwan
}

\section{Keywords}

Maintenance pemetrexed · Oligoprogression · Stereotactic ablative radiotherapy

\begin{abstract}
Maintenance pemetrexed offers survival benefit with well-tolerated toxicities for advanced non-squamous non-small cell lung cancer (NSCLC). We present 3 consecutively enrolled patients with advanced non-squamous NSCLC, receiving stereotactic ablative radiotherapy (SABR) for oligoprogressive disease during maintenance pemetrexed. All of them had sustained local control of thoracic oligoprogression after the SABR, while maintenance pemetrexed were kept for additionally long progression-free interval. SABR targeting oligoprogression with continued pemetrexed is an effective and safe approach to extend exposure of maintenance pemetrexed, thus maximizing the benefit from it.
\end{abstract}




\section{Introduction}

Recent phase III trials have demonstrated the benefits of maintenance therapy with pemetrexed for metastatic non-small cell lung cancer (NSCLC) [1, 2]. Pemetrexed maintenance therapy improved progression-free survival and overall survival by both continuation and switch maintenance strategies. With the support of emerging evidence, oncologists have become accustomed to prolonging the administration of cytotoxic pemetrexed for advanced NSCLC, similar to the use of molecular targeting agents for anaplastic lymphoma kinase (ALK)-positive or epidermal growth factor receptor (EGFR)-mutant NSCLC [3]. However, disease progression during maintenance pemetrexed is almost inevitable after a median progression-free survival of 4-6 months. Local ablative therapies for oligoprogressive disease (OPD), including surgery, radiofrequency ablation, and stereotactic ablative radiotherapy (SABR) have been reported to extend survival with continued tyrosine kinase inhibitors (TKI) for ALK-positive or EGFR-mutant lung cancer [4, 5]. A preliminary report from a phase II trial demonstrated prolonged progression-free survival in oligo-metastatic NSCLC patients receiving local consolidative therapy for non-progressive disease, compared to systemic therapy alone [6]. However, there have been no previous investigations on local ablative therapy for OPD in patients receiving maintenance pemetrexed. Here, we present our preliminary results of SABR eradicating progressive lesions with the continued use of pemetrexed.

\section{Patients and Methods}

Patients diagnosed with advanced lung adenocarcinoma were treated with pemetrexed in combination with cisplatin/carboplatin as the first-line treatment, or as the salvage regimen, after systemic progression under TKI. Maintenance pemetrexed $\left(500 \mathrm{mg} / \mathrm{m}^{2}\right)$ in a 21 day cycle was given after four to six cycles of the initial pemetrexed/platinum if there was no disease progression. Response Evaluation Criteria in Solid Tumors (RECIST) version 1.1 for imaging studies was adopted to evaluate treatment responses. Patients with oligoprogression ( $\leq 5$ discrete progressing lesions) that continued to derive systemic benefits from pemetrexed were prospectively enrolled to receive SABR for locoregional disease. Meanwhile, pemetrexed was continued until further systemic progression not suitable for local therapy developed. Treatment-related toxicities were scored according to Common Terminology Criteria for Adverse Events (CTCAE) version 4.0. Here, we present three consecutively enrolled cases receiving SABR for thoracic oligoprogression under pemetrexed with $>18$ months of clinical and imaging follow-up.

\section{Case Report}

Case 1 involves a 55-year-old woman with stage IV EGFR-mutant (Del19/L858R) NSCLC, presenting with multiple lung tumors and pleural nodular seeding. She initially responded to gefitinib, but 5 months later developed enlarged left upper-lung tumors and increased pleural nodularity. Six cycles of pemetrexed/cisplatin achieved partial remission, and maintenance pemetrexed was given after the induction treatment. After six cycles of maintenance pemetrexed, slight enlargement of the left lung tumors and pleural lesions were noted by computed tomography (CT) of the chest, without other systemic progres- 


\section{Case Reports in Oncology}

sions. She underwent SABR via Cyberknife targeting on oligoprogressive tumors (five lesions in total), each with 20-22 Gy in a single fraction on 5 separate days. Repeat chest imaging 2 and 4 months later demonstrated stationary thoracic disease with grade 1 radiation pneumonitis (fig. 1a). Maintenance pemetrexed was continued for an additional 10 cycles until new nodular lesions in the left lung developed 7 months after SABR. The patient started erlotinib 1 year after the pemetrexed regimen. There were no apparent toxicities during the maintenance pemetrexed. She later developed T790M mutations and spine metastases with subsequent failure of erlotinib and gemcitabine, while her chest disease remained relatively stable 2 years after the SABR.

Case 2 is a 71-year-old man with metastatic EGFR-mutated adenocarcinoma of the lung. He received first-line afatinib and palliative radiotherapy for a metastatic lesion at T8 of the spine. The primary tumor in his left upper lung initially regressed but demonstrated apparent enlargement 7 months later. Pemetrexed/cisplatin were given for salvage treatment, and the tumor showed partial regression. Then, the patient underwent maintenance pemetrexed after six cycles of induction doublet regimen. He remained on tri-weekly pemetrexed for 2 years with good locoregional and systemic disease control. Only mild toxicities, such as grade 1 fever, grade 1 anemia/eosinophilia, and grade 1 gastrointestinal discomfort occurred during the maintenance treatment. Follow-up chest CT revealed enlargement of the primary tumor, with no evidence of extra-thoracic progression. Exertional dyspnea and chest pain also developed. SABR targeted the tumor in his left upper lung with 44 Gy in four fractions. The tumor regressed after SABR treatment and has been unchanged for 2 years with postradiation fibrotic changes (fig. 1b). Currently, the patient has remained on maintenance pemetrexed for more than 48 months with no evidence of disease recurrence.

Case 3 demonstrates a 63-year-old man diagnosed with stage IIA (T1bN1M0) NSCLC in September 2006. He underwent curative surgery and four cycles of adjuvant cisplatin/ vinorelbine. It had been uneventful until January 2010, when mediastinal recurrence developed. The patient underwent salvage radiotherapy with $60 \mathrm{~Gy}$ in 25 fractions to the recurrent mediastinal lymphadenopathies. He responded with complete metabolic regression. In August 2012, he developed a right hilar mass and a new nodular lesion in the left upper lobe, without other systemic relapse. Bronchoscopic biopsy confirmed recurrent ALK-positive adenocarcinoma. Salvage pemetrexed/carboplatin were given and maintenance pemetrexed was started after six cycles of induction treatment. He had good response of thoracic disease in serial follow-up imaging studies, until an oligoprogressive tumor at the left upper lobe showed enlargement after 14 cycles of maintenance pemetrexed. He received SABR to the left upper lung tumor with 45 Gy in 3 fractions in December 2013. The patient has remained on maintenance pemetrexed for non-progressive disease at this time with grade 1 fatigue and radiation fibrosis (fig. 1c).

\section{Discussion}

Survival benefits for patients with advanced NSCLC carried out by maintenance pemetrexed have been clearly demonstrated by a series of clinical trials [1-3]. Pemetrexed, as a multi-targeted folate antimetabolite, is well tolerated during long-term use. In the PARAMOUNT trial, more than one third of patients allocated to the maintenance arm received more than six cycles of pemetrexed without worsening quality of life [7]. Though numerous questions were left unanswered regarding optimal patient selection, multi-agent regimens, and administration duration of maintenance pemetrexed. For non-progressive advanced 
non-squamous NSCLC, oncologists have recently tended to prescribe maintenance pemetrexed in a similar way as for TKI, which is uninterruptedly until disease progression.

OPD arises from subclone expansion resistant to ongoing treatment, and is an early state of disease progression. Before the dissemination of resistant subclones becomes the predominant burden of the patient, OPD with a limited number of isolated regions amenable to local ablative therapy offers a chance to delay the start of overwhelming progression. Local ablative therapy for OPD prevents the early termination of the ongoing treatment, while there is still effective systemic disease suppression by the current regimen. Gomez et al. [6] recently reported local therapy prolonged progression-free survival in advanced NSCLC with non-progressive disease after initial systemic treatment, demonstrating the value of aggressive local treatment on consolidating disease control. By contrast, in this case series, we showed that SABR targeting OPD prolonged the treatment with pemetrexed, maintaining clinical benefits (table 1).

SABR is an effective tool at controlling local disease in OPD under TKI $[4,5,8]$ or oligometastases [8]. In this report, all patients had sustained local control of thoracic oligoprogression after the SABR, while there was only mild radiation-related pneumonitis/fibrosis. With only one case having her second progression during follow-up, all of them had longer time-to-further-progression than their initial progression-free time under maintenance pemetrexed, reflecting apparent benefits from SABR. In the PARAMOUNT trial, superior survival outcomes were observed in patients receiving longer exposure to pemetrexed [1]. In this series, all 3 patients received more than 10 cycles of maintenance pemetrexed in total. Two patients with long progression-free intervals before SABR also continued additional pemetrexed treatment ( 12 cycles in average) without a second progression.

The extended use of maintenance pemetrexed could be attributed to not only early elimination of drug-resistant subclones by SABR, but also the interactions between the pemetrexed response and driver oncogene mutations. Lee et al. [9] reported that for patients with ALK-positive NSCLC, the time-to-progression under pemetrexed was significantly longer compared to that of patients with EGFR mutations and ALK-negative/EGFR wild-type control groups. Although the underlying molecular basis behind the different responses to pemetrexed remains unclear, Berge et al. [10] have demonstrated that pemetrexed exposure in crizotinib-naïve patients did not affect subsequent crizotinib outcomes after pemetrexed failed. Recently, a cost-effectiveness analysis on molecular testing of ALK-gene rearrangement and first-line therapy with crizotinib for patients with advanced NSCLC showed that early detection with ALK-targeted inhibition in ALK-positive cases is not cost-effective [11]. In the present report, we demonstrated that for OPD during maintenance pemetrexed, SABR successfully extended the time of effective systemic disease suppression by pemetrexed, thus reserving the high expenses of tests for ALK-driver mutation and possible crizotinib use for definite systemic failure. This combined-modality strategy should be considered first, especially in low-income or developing countries, where resources for second-line treatment after pemetrexed failure are much more limited.

To our knowledge, this is the first report indicating that SABR targeting oligoprogression with continued maintenance pemetrexed is an effective approach for patients with advanced non-squamous NSCLC. Although the true benefits from SABR during maintenance pemetrexed warrants a clear demonstration by a randomized trial, this consecutive case series shows that a subset of patients receiving SABR during maintenance pemetrexed for OPD can experience long-term disease control without severe treatment-related toxicities, in a similar way to those with driver mutations receiving targeted therapy. Further work with defined treatment criteria and larger sample sizes is necessary. 
Lu et al: Maximizing Benefits from Maintenance Pemetrexed with Stereotactic Ablative Radiotherapy in Oligoprogressive Non-Squamous Non-Small Cell Lung Cancer

\section{Statement of Ethics}

The study was conducted according to The Declaration of Helsinki Principles. The authors have no conflicts of ethics to disclose.

\section{Disclosure Statement}

The authors have no conflicts of interest to disclose.

\section{References}

1 Paz-Ares LG, de Marinis F, Dediu M, Thomas M, Pujol JL, Bidoli P, Molinier O, Sahoo TP, Laack E, Reck M, Corral J, Melemed S, John W, Chouaki N, Zimmermann AH, Visseren-Grul C, Gridelli C: PARAMOUNT: Final overall survival results of the phase III study of maintenance pemetrexed versus placebo immediately after induction treatment with pemetrexed plus cisplatin for advanced nonsquamous nonsmall-cell lung cancer. J Clin Oncol 2013;31:2895-2902.

2 Ciuleanu T, Brodowicz T, Zielinski C, Kim JH, Krzakowski M, Laack E, Wu YL, Bover I, Begbie S, Tzekova V, Cucevic B, Pereira JR, Yang SH, Madhavan J, Sugarman KP, Peterson P, John WJ, Krejcy K, Belani CP: Maintenance pemetrexed plus best supportive care versus placebo plus best supportive care for nonsmall-cell lung cancer: a randomised, double-blind, phase 3 study. Lancet 2009;374:1432-1440.

-3 Gerber DE: Maintenance therapy for advanced lung cancer: who, what, and when? J Clin Oncol 2013;31:2983-2990.

4 Gan GN, Weickhardt AJ, Scheier B, Doebele RC, Gaspar LE, Kavanagh BD, Camidge DR: Stereotactic radiation therapy can safely and durably control sites of extra-central nervous system oligoprogressive disease in anaplastic lymphoma kinase-positive lung cancer patients receiving crizotinib. Int J Radiat Oncol Biol Phys 2014;88:892-898.

5 Yu HA, Sima CS, Huang J, Solomon SB, Rimner A, Paik P, Pietanza MC, Azzoli CG, Rizvi NA, Krug LM, Miller VA, Kris MG, Riely GJ: Local therapy with continued EGFR tyrosine kinase inhibitor therapy as a treatment strategy in EGFR-mutant advanced lung cancers that have developed acquired resistance to EGFR tyrosine kinase inhibitors. J Thorac Oncol 2013;8:346-351.

6 Gomez DR, Blumenschein GR, Lee JJ, Hernandez M, Camidge R, Doebele RC, Gaspar LE, Gibbons DL, Karam JA, Kavanagh BD, Komaki R, Louie AV, Palma DA, Tsao AS, Nassib W, Zhang J, Swisher S, Heymach J: Local consolidative therapy (LCT) to improve progression-free survival (PFS) in patients with oligometastatic non-small cell lung cancer (NSCLC) who receive induction systemic therapy (IST): results of a multi-institutional phase II randomized study. J Clin Oncol 2016;34(suppl; abstr 9004).

7 Gridelli C, de Marinis F, Pujol JL, Reck M, Ramlau R, Parente B, Pieters T, Middleton G, Corral J, Winfree K, Melemed S, Zimmermann A, John W, Beyrer J, Chouaki N, Visseren-Grul C, Paz-Ares LG: Safety, resource use, and quality of life in paramount: a phase III study of maintenance pemetrexed versus placebo after induction pemetrexed plus cisplatin for advanced nonsquamous non-small-cell lung cancer. J Thorac Oncol 2012;7:1713-1721.

-8 Westover KD, Iyengar P, Sharma AN, Timmerman R: SABR for aggressive local therapy of metastatic cancer: a new paradigm for metastatic non-small cell lung cancer. Lung Cancer 2015;89:87-93.

$\checkmark 9$ Lee JO, Kim TM, Lee SH, Kim DW, Kim S, Jeon YK, Chung DH, Kim WH, Kim YT, Yang SC, Kim YW, Heo DS, Bang YJ: Anaplastic lymphoma kinase translocation: a predictive biomarker of pemetrexed in patients with non-small cell lung cancer. J Thorac Oncol 2011;6:1474-1480.

-10 Berge EM, Lu X, Maxson D, Baron AE, Gadgeel SM, Solomon BJ, Doebele RC, Varella-Garcia M, Camidge DR: Clinical benefit from pemetrexed before and after crizotinib exposure and from crizotinib before and after pemetrexed exposure in patients with anaplastic lymphoma kinase-positive non-small-cell lung cancer. Clin Lung Cancer 2013;14:636-643.

11 Djalalov S, Beca J, Hoch JS, Krahn M, Tsao MS, Cutz JC, Leighl NB: Cost effectiveness of EML4-ALK fusion testing and first-line crizotinib treatment for patients with advanced ALK-positive non-small-cell lung cancer. J Clin Oncol 2014;32:1012-1019. 


\section{Case Reports in Oncology}

\begin{tabular}{l|l}
\hline Case Rep Oncol 2016;9:474-480 \\
\hline $10.1159 / 000448804$ & $\begin{array}{l}\text { (c) 2016 The Author(s). Published by S. Karger AG, Basel } \\
\text { www.karger.com/cro }\end{array}$ \\
\hline
\end{tabular}

Lu et al: Maximizing Benefits from Maintenance Pemetrexed with Stereotactic Ablative Radiotherapy in Oligoprogressive Non-Squamous Non-Small Cell Lung Cancer

a

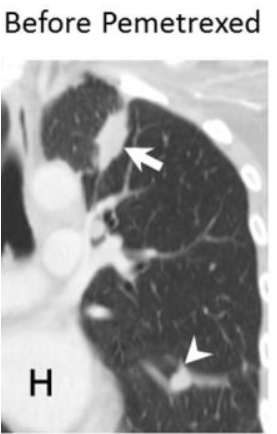

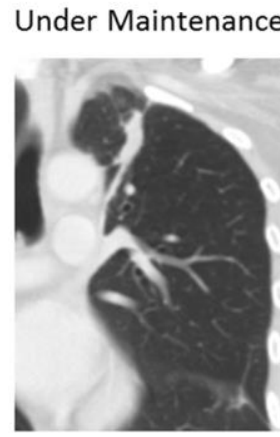

Before SABR

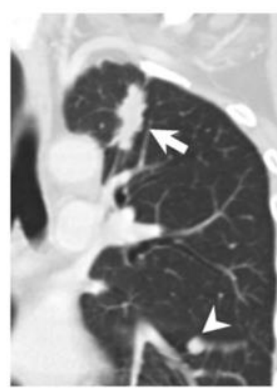

Before SABR

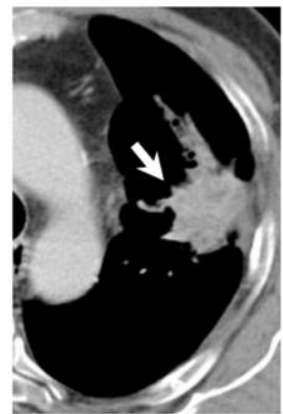

Before SABR
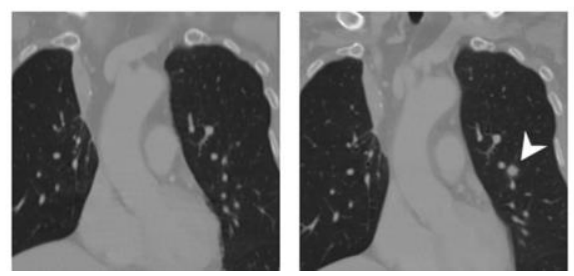

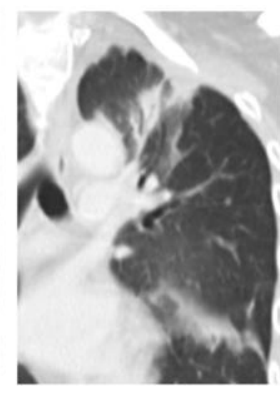

3 Months

2 Months

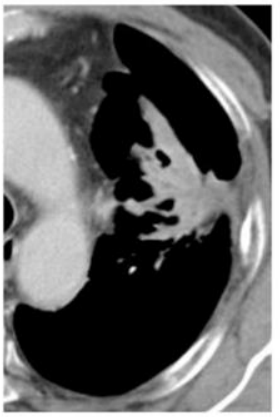

2 Months

12 Months

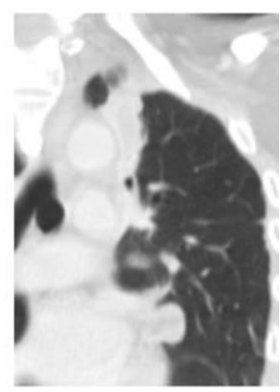

22 Months

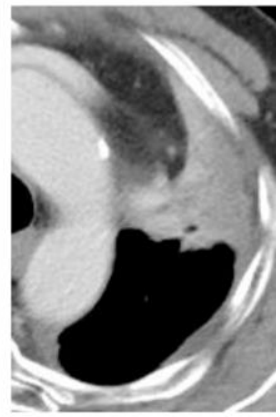

16 Months
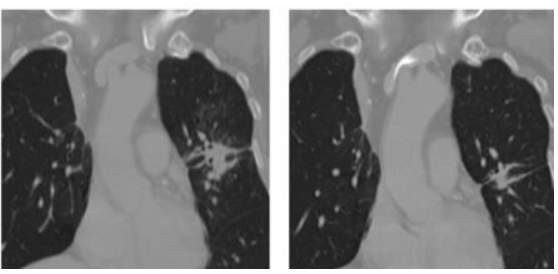

Fig. 1. Treatment response on CT in patients undergoing SABR for oligoprogression during maintenance pemetrexed. a Case 1 involves a primary tumor at the left upper lung and multiple metastatic lung/pleural lesions. Coronal view, post-contrast series showing the progression of the primary tumor (arrow) and one of the metastatic tumors (arrowhead) after the initial response to pemetrexed. They both responded well to SABR with post-irradiation fibrosis. $\mathrm{H}=$ Heart. b Axial view, post-contrast series of case 2 showing the primary tumor at the left lung (arrow) enlarging after the initial response to pemetrexed. The tumor showed marked shrinkage and fibrotic change after SABR without relapse. A = Aorta. c Coronal view, postcontrast series of case 3 showing apparent response of a large recurrent tumor at the right upper lung (asterisk) after pemetrexed. An enlarging metastatic tumor at the left lung (arrowhead) during maintenance pemetrexed was salvaged by SABR. 
Lu et al.: Maximizing Benefits from Maintenance Pemetrexed with Stereotactic Ablative Radiotherapy in Oligoprogressive Non-Squamous Non-Small Cell Lung Cancer

Table 1. Characteristics of patients receiving SABR for oligoprogression under maintenance pemetrexed

\begin{tabular}{|c|c|c|c|c|c|c|c|c|c|c|}
\hline $\begin{array}{l}\text { Case } \\
\text { No. }\end{array}$ & $\begin{array}{l}\text { Age, } \\
\text { years }\end{array}$ & $\begin{array}{l}\text { Driver } \\
\text { mutation }\end{array}$ & $\begin{array}{l}\text { Previous } \\
\text { TKI }\end{array}$ & $\begin{array}{l}\text { Maintenance } \\
\text { pemetrexed } \\
\text { before OPD }\end{array}$ & $\begin{array}{l}\text { Site and } \\
\text { number of } \\
\text { OPD }\end{array}$ & $\begin{array}{l}\text { SABR } \\
\text { regimen }\end{array}$ & $\begin{array}{l}\text { Response } \\
\text { of OPD }\end{array}$ & $\begin{array}{l}\text { Late radiation } \\
\text { toxicity }\end{array}$ & $\begin{array}{l}\text { Time to } \\
\text { further } \\
\text { progression }\end{array}$ & $\begin{array}{l}\text { Additional } \\
\text { cycles of } \\
\text { pemetrexed }\end{array}$ \\
\hline 1 & 55 & EGFR & yes & $\begin{array}{l}5 \text { months } \\
6 \text { cycles }\end{array}$ & $\begin{array}{l}\text { lung } \\
\text { (primary } \\
\text { and } \\
\text { metastatic), } \\
\text { pleura } \\
\mathrm{n}=5\end{array}$ & $\begin{array}{l}20-22 \mathrm{~Gy} \\
\text { in single } \\
\text { fractions }\end{array}$ & & $\begin{array}{l}\text { pneumonitis, } \\
\text { grade } 1\end{array}$ & 7 months & 10 cycles \\
\hline 2 & 71 & EGFR & yes & $\begin{array}{l}23 \text { months } \\
32 \text { cycles }\end{array}$ & $\begin{array}{l}\text { lung } \\
\text { (primary) } \\
n=1\end{array}$ & $\begin{array}{l}44 \text { Gy in } \\
4 \text { frac- } \\
\text { tions }\end{array}$ & PR & $\begin{array}{l}\text { pneumonitis, } \\
\text { grade } 1 \text {; } \\
\text { chest wall } \\
\text { pain, grade } 2\end{array}$ & $\begin{array}{l}\text { no } \\
\text { progression } \\
\text { in } 24 \text { months }\end{array}$ & $19+$ cycles $^{1}$ \\
\hline 3 & 63 & ALK & no & $\begin{array}{l}11 \text { months } \\
14 \text { cycles }\end{array}$ & $\begin{array}{l}\text { lung } \\
\text { (metastatic) } \\
n=1\end{array}$ & $\begin{array}{l}45 \text { Gy in } \\
3 \text { frac- } \\
\text { tions }\end{array}$ & SD & $\begin{array}{l}\text { pneumonitis, } \\
\text { grade } 1\end{array}$ & $\begin{array}{l}\text { no } \\
\text { progression } \\
\text { in } 16 \text { months }\end{array}$ & $7+$ cycles $^{1}$ \\
\hline
\end{tabular}

${ }^{1}$ Indicates patients who have not progressed and been undergoing pemetrexed during study follow-up. PR = partial response; $\mathrm{SD}=$ stable disease. 